\title{
Impact of Umbilical Cord Arterial pH, Gestational Age, and Birth Weight on Neurodevelopmental Outcomes for Preterm Neonates
}

\author{
Roksana Malak ${ }^{\text {Corresp., } 1}$, Dorota Sikorska ${ }^{2}$, Marta Rosołek ${ }^{3}$, Ewa Baum ${ }^{4}$, Ewa Mojs ${ }^{5}$, Przemysław Daroszewski ${ }^{6}$, \\ Monika Matecka ${ }^{7}$, Brittany Fechner $^{2}$, Włodzimierz Samborski ${ }^{2}$ \\ 1 Department and Clinic of Rheumatology, Rehabilitation and Internal Diseases, Poznan University of Medical Science, Poznań, Poland, Poznań, \\ wielkopolskie, Great Poland, Polska \\ 2 Department and Clinic of Rheumatology, Rehabilitation and Internal Diseases, Poznan University of Medical Science, Poznan, Polska \\ 3 Department of Physiotherapy, Poznan University of Medical Science, Poznań, Poland, Poznan University of Medical Science, Poznan, Polska \\ 4 Department of Social and Human Science, Poznan University of Medical Science, Poznań, Poland, Poznan University of Medical Science, Poznan, Polska \\ 5 Department of Clinical Psychology, Poznan University of Medical Sciences, Poznań, Poland, Poznan University of Medical Science, Poznan, Polska \\ 6 Department of Organization and Management in Health Care, Poznan University of Medical Sciences, Poznań, Poland, Poznan University of Medical \\ Science, Poznan, Polska \\ 7 Department of Geriatrics and Gerontology, Poznan University of Medical Sciences, Poznań, Poland, Poznan University of Medical Science, Poznan, Polska \\ Corresponding Author: Roksana Malak \\ Email address: rmalak@ump.edu.pl
}

Background. The aim of this study was to determine the impact of umbilical cord arterial $\mathrm{pH}$, gestational age, and birth weight on neurodevelopmental outcomes for preterm neonates. Methods. We examined 112 neonates. Inclusion criteria were: Saturations greater than 88\%, and heart rates between 100-205 beats per minute. Measurements. We assessed several neurodevelopmental factors as part of the Brazelton Neonatal Behavioral Assessment Scale (NBAS), $4^{\text {th }}$ edition, such as asymmetric tonic neck reflex (ATNR), motor maturity, response to sensory stimuli, habituation, and state regulation. Initial assessment parameters such as APGAR score and umbilical cord arterial pH were used to assess neonates. Results. We found a strong correlation between the presence of the sucking reflex and umbilical cord arterial $\mathrm{pH}(\mathrm{r}=0.32 ; p=0.018981)$. Umbilical cord arterial $\mathrm{pH}$ was also correlated with the presence of asymmetric tonic neck reflex $(r=0.27$; $p=0.047124)$, cost of attention $(r=0.31 ; p=0.025381)$ and general motor maturity $(r=0.34 ; p=0.011741)$. Conclusions. We found that the sucking reflex may be affected in infants with low umbilical cord arterial $\mathrm{pH}$ values. Practitioners and parents can use the NBAS to help determine neurodevelopmental factors and outcomes in preterm infants, possibly leading to safer and more effective feeding practices and interventions. 


\section{Impact of Umbilical Cord Arterial pH, Gestational Age, and} 3 Birth Weight on Neurodevelopmental Outcomes for Preterm 4 Neonates

6 Roksana Malak ${ }^{1}$, Dorota Sikorska ${ }^{1}$, Marta Rosołek ${ }^{2}$, Ewa Baum ${ }^{3}$, Ewa Mojs ${ }^{4}$, Przemysław

7 Daroszewski $^{5}$, Monika Matecka ${ }^{6}$, Brittany Fechner ${ }^{1}$, and Włodzimierz Samborski ${ }^{1}$

$9{ }^{1}$ Department and Clinic of Rheumatology, Rehabilitation and Internal Diseases, Poznań

10 University of Medical Sciences, Poznań, Poland

112 Department of Physiotherapy, Poznań University of Medical Sciences, Poznań, Poland

$12{ }^{3}$ Department of Social and Human Science, Poznań University of Medical Sciences, Poznań, 13 Poland

$14{ }^{4}$ Department of Clinical Psychology, Poznań University of Medical Sciences, Poznań, Poland

$15{ }^{5}$ Department of Organization and Management in Healthcare, Poznań University of Medical

16 Sciences, Poznań, Poland

$17{ }^{6}$ Department of Geriatrics and Gerontology, Poznań University of Medical Sciences, Poznań, 18 Poland

Corresponding Author:

Roksana Malak ${ }^{1}$ (D) https://orcid.org/0000-0003-0521-5249

22 Collegium Maius, 28 Czerwca 1956 r. 135/147 61-544, Poznań, Poland

23 We have no conflict of interest to disclose.

24 Correspondence concerning this article should be addressed to Roksana Malak,

25 Email address: rmalak@ump.edu.pl 


\section{Abstract}

27 Background. The aim of this study was to determine the impact of umbilical cord arterial $\mathrm{pH}$, 28 gestational age, and birth weight on neurodevelopmental outcomes for preterm neonates.

29 Methods. We examined 112 neonates. Inclusion criteria were: Saturations greater than $88 \%$, and 30 heart rates between $100-205$ beats per minute.

31 Measurements. We assessed several neurodevelopmental factors as part of the Brazelton

32 Neonatal Behavioral Assessment Scale (NBAS), $4^{\text {th }}$ edition, such as asymmetric tonic neck

33 reflex (ATNR), motor maturity, response to sensory stimuli, habituation, and state regulation.

34 Initial assessment parameters such as APGAR score and umbilical cord arterial $\mathrm{pH}$ were used to 35 assess neonates.

36 Results. We found a strong correlation between the presence of the sucking reflex and umbilical 37 cord arterial $\mathrm{pH}(\mathrm{r}=0.32 ; p=0.018981)$. Umbilical cord arterial $\mathrm{pH}$ was also correlated with the 38 presence of asymmetric tonic neck reflex $(\mathrm{r}=0.27 ; p=0.047124)$, cost of attention $(\mathrm{r}=0.31 ; p=$ $390.025381)$ and general motor maturity $(\mathrm{r}=0.34 ; p=0.011741)$.

40 Conclusions. We found that the sucking reflex may be affected in infants with low umbilical

41 cord arterial $\mathrm{pH}$ values. Practitioners and parents can use the NBAS to help determine

42 neurodevelopmental factors and outcomes in preterm infants, possibly leading to safer and more 43 effective feeding practices and interventions. 


\section{Introduction}

46 Feeding problems are one of the most common issues encountered in pediatric care,

47 occurring in approximately one-fourth of healthy children and up to $90 \%$ of children at risk for

48 developmental delay (Barton et al., 2018; Clawson et al., 2008). The discharge of infants from

49 hospital neonatal units is often postponed or delayed due to an infant's inability to suck and feed

50 safely (Lau, 2015). Although the sucking reflex appears initially in fetal life, not all neonates

51 present a sucking reflex after delivery. Feeding problems in premature infants vary, appearing in

$5226.8 \%$ of low birthweight infants and $40 \%$ of premature infants aged between $25-37$ weeks

53 gestation (Harding et al., 2018). The inability to orally feed can delay discharge from a neonatal

54 care unit (Poore et al., 2008).

Preterm infants tend to have problems with the coordination of breathing, sucking, and

56 swallowing, which can lead to respiratory difficulties with feeding (Gewolb et al., 2001; Harding et al., 2018). According to Greene, et al. (2016), an infant's breathing pattern is not only essential for effective sucking but also for the ability to coordinate the muscles of the jaw, lips, tongue, palate, pharynx, upper trunk muscle tone, and normal sensory function. The Neonatal Behavioral Assessment Scale (NBAS) can be used to measure some of the aforementioned abilities.

Erlandsson et al. (2007) used the NBAS in their study and found that early tactile stimulation by skin-to-skin contact can help develop an infant's prefeeding behavior.

According to Foster, et al. (2016) and Greene et al. (2016), nonnutritive sucking allows for a faster transition to nutritive sucking, or full oral feeding, for an infant. Thanks to the diagnosis of neurobehavioral problems including sucking behavior (for instance by, the NBAS), a therapist can plan and apply proper and direct therapeutic interventions such as improving muscle tone, sensory function, and coordination to properly develop sucking and eating. It has 
68 been shown that at about the $12^{\text {th }}$ week of gestation a fetus can swallow and at about the $15^{\text {th }}$

69 week of gestation the fetus can suck (Reissland et al., 2012; Zhang et al. 2017). Posterior-

70 anterior movements of the tongue and jaw are observed at 18 to 24 weeks gestation and are

71 important for developing the sucking response (da Costa et al., 2008).

72 The coordination of sucking and swallowing appears at about 32 to 40 weeks of

73 gestation, while the coordination between sucking, swallowing and breathing appears between

74 34- and 42-weeks post-conception (da Costa et al., 2008; Gewolb et al., 2001; Gewolb et al.

75 2006). However, clinicians and researchers have found that premature infants born before 37

76 weeks of gestation can be successfully bottle fed, despite neurological immaturity (Simpson et

77 al., 2002). Knowledge surrounding the diagnosis of feeding problems should be improved in

78 order to facilitate proper feeding therapy (Gewolb et al., 2001). The oral-motor maturation

79 process correlates with the emergence of motor pathways and the development of the central

80 nervous system. Furthermore, Kirk et al. (2007) found that in order to achieve earlier attainment

81 of full oral feeding, they could apply infant behavioral readiness signs and hunger cues to a more

82 general population of premature infants. Feeding readiness is an important part of infant feeding

83 development. Factors such as birth weight and gestational age may relate to feeding readiness

84 and efficiency and should be investigated and taken into consideration prior to instituting an oral

85 feeding intervention. This is a situation in which a physical therapy intervention might not be

86 recommended due to a neonate's immaturity (Gewolb et al., 2001).

87 Feeding readiness behaviors (FRBs) may have an effect on future feeding efficiency in

88 preterm infants (White-Traut et al., 2005). It is crucial for therapists to recognize neurological

89 immaturity, neurodevelopmental delays, and neurobehavioral stability as a foundation for

90 complex neuromotor activity such as oral feeding (Desai \& Lim, 2019). Strengthening and 
91 developing a neonate's neurodevelopment may improve his or her oral feeding ability, but an

92 intervention should be applied after first assessing his or her development and maturity (Li et al.,

93 2020). Neonates are classified as preterm infants when early gestational age presents insufficient

94 behavioral abilities and oral feeding difficulties (Li et al., 2020). Even if an infant is at about 26

95 weeks of gestation or older, a child will still improve in his or her neurodevelopment (Ohnishi et

96 al., 2016). Other infant characteristics such as congenital heart defects, early surgical

97 intervention, postsurgical complications, difficulties in achieving stability in physiological and

98 behavioral subsystems, poor arousal, muscle tone abnormalities, and poor state regulation may

99 affect a neonate's ability to achieve oral feeding readiness (Desai \& Lim, 2019).

100 The sucking reflex is just one of approximately 50 primitive neonatal reflexes (PNRs).

101 Other PNRs include the rooting reflex and jaw jerk reflex which give valuable information

102 regarding the neurological condition of the neonate. However, the sucking reflex has been

103 identified as the most important for feeding. Other neurodevelopmental aspects of neurobehavior

104 such as the asymmetric tonic neck reflex, the Glabellar reflex, the plantar reflex, the Galant

105 reflex, the walking reflex, and the grasping reflex should be also considered during the

106 assessment of a neonate (Salandy et al., 2019; Zaferiou, 2004).

107 However, problems with sucking may be a risk factor for the neonate potentially

108 experiencing adverse neurodevelopmental issues, such as problems with feeding (Harding et al.,

109 2018; Zhang et al., 2017). Sucking might provide a predictive value for short-term

110 neurodevelopmental outcomes (McGrath \& Braescu, 2004; Zhang et al., 2017). In the first two

111 years of life, despite many factors that may interfere with an infant's feeding behavior, sucking

112 behavior is an early marker of abnormal developmental outcomes (Wolthuis-Stigter et al., 2015).

113 It is not only reflexes that are essential for effective feeding. Immature motor skills, hypotonia, 
114 an immature neurological system, and sensory development can contribute to underdeveloped

115 sucking skills (Harding et al., 2018). Furthermore, the following factors are important when

116 introducing oral interventions with infants: Overall development, gestational age, developing

117 swallowing skills before sucking, physiological stability, health status, the development and

118 interpretation of infant oral readiness signs, and early communication (Dodrill et al., 2008;

119 Harding et al., 2018). The NBAS is able to assess all of the above-mentioned factors. One

120 advantage of the NBAS is that it takes into consideration the behavior of a child, including non-

121 nutritive sucking which should be assessed while preparing an infant to be fed (Dodrill et al.,

122 2008; Kirk et al., 2007).

123 Additionally, proper positioning of the infant plays an important role during feeding time

124 (Colson et al., 2008). The most recommended position during feeding time is the elevated side-

125 lying position (Clark et al, 2007). Further studies may be warranted regarding proper positioning

126 of the infant, for example using the chin-tuck position. The chin-tuck position and chin tuck

127 against resistance (CTAR) exercise may help in preventing dysphagia because the position

128 enables the proper suprahyoid muscle contraction necessary for the proper working of the tongue

129 (Park et al., 2020; Redstone \& West, 2004; The Emily Center at Phoenix's Children's Hospital,

130 2016; Yoon et al., 2014). The most important benefit of the chin-tuck position is that it has been

131 widely used to prevent aspiration difficulties in patients with dysphagia. Ra et al. (2014)

132 performed a study in order to investigate the effectiveness of feeding and the degree of optimal

133 neck flexion thanks to the chin-tuck position. Aspiration was reduced or eliminated when the

134 chin-tuck position was used with the study's participants which was shown in their

135 Videofluoroscopic Swallow Study (VFSS). The proper position with clear respiratory and

136 digestive tracts (good position of the esophagus and larynx) helped with swallowing in a safe 
137 way. The chin-tuck position reduced the distance between the thyroid and the hyoid and the

138 distance between the mandible and the hyoid (Bond et al., 2020; Bülow et al., 2001; Ra et al.,

139 2014; Versfeld, 2018; Welch et al., 1993). Therefore, the chin-tuck position is important for

140 ensuring that the infant is in a safe position in order to breathe and suck at the same time.

141 Assessment tools such as the NBAS are recommended to assess an infant's

142 neurodevelopment and potentially find any underlying somatic disorders. Infants who present

143 with somatic disorders may encounter challenges with the sucking reflex due to being less

144 reactive to external stimuli (Belot et al., 2021). It should be noted that if the infant being assessed

145 becomes overreactive to stimuli or experiences other medical issues this may interfere with the

146 implementation of the NBAS assessment (Brazelton \& Nugent, 2011). The aim of this study was

147 to determine the impact of umbilical cord arterial $\mathrm{pH}$, gestational age, and birth weight on

148 neurodevelopmental outcomes for preterm neonates.

\section{Materials \& Methods}

150 We examined a cohort of 112 infants hospitalized at the Gynecology and Obstetrics

151 Clinical Hospital, all of whom presented with feeding problems. Parents were given informed

152 consent the day of the assessment. All parents provided their written informed consent prior to

153 the assessment of their child. According to the physician's and neonatologist's report, neonates

154 who were included in the study were considered neurodevelopmentally immature and presented

155 problems with feeding. Common comorbidities among study participants included:

156 Intraventricular hemorrhage (6 patients), bronchopulmonary dysplasia (66 patients), and patients

157 after an intrauterine infection (18 patients). These comorbidities are the reason why they were

158 initially hospitalized. The range of gestational age was wide: Between 22 and 40 weeks of

159 gestation, and the gestational age at the assessment ranged between 30 and 41 weeks. 
161 heart rate between 100-205 beats per minute as measured by the Nellcor OxiMax N-600x pulse

162 oximeter. Pulse oximetry was measured on the sole of the foot (Sink et al., 2011). Any infants

163 manifesting with clinical instability such as a high temperature, fatigue or deviation of $\mathrm{SpO}_{2}$ or a

164 heart rate outside of the aforementioned parameters were excluded from the study. The exclusion

165 criteria therefore included desaturation $\left(\mathrm{SpO}_{2}<88 \%\right)$, a heart rate $<100$ or $>205$ beats per

166 minute, active inflammation, sepsis, bone replacement, tumor, encephalopathy, hypotension and

167 lethal birth defects (e.g. Edwards, Patau etc.) Following the application of inclusion and

168 exclusion criteria, 100 subjects were recruited to the study. Twelve neonates did not meet

169 inclusion crtieria, since their oxygen saturaion was below $88 \mathrm{bpm}$ and their heart rate was heart

170 rate was $<100$ or $>205$ beats per minute. Although there were 112 neonates recruited at the

171 beginning of the study, just 100 met inclusion criteria, and 84 of these 100 neonates exhibited

172 insufficient sucking behavior.

173 We assessed the study's participants using the NBAS just one time in the span of three

174 months, which was not the routine in the neonatal unit. We used the NBAS to check the

175 neonates' maturity and neurobehavior, which including sucking behavior. The average age of

176 gestation was $32 \pm 6$ weeks (minimum 22 weeks postmenstrual age and maximum 40 weeks

177 postmenstrual age). The average gestational age of the infants during the time of the NBAS

178 assessment was $35 \pm 3$ and varied between 30 and 41 weeks, postmenstrual age. The average

179 birth weight was $1808 \mathrm{~g} \pm 679 \mathrm{~g}$.

\section{Measurements}

181 We assessed infant neurobehavior, including sucking, using the Brazelton Neonatal

182 Behavioral Assessment Scale (NBAS), $2^{\mathrm{ND}}$ edition as other researchers have done (Tokunaga et 
183 al., 2019). Our research study did not evaluate the nutritive sucking development for the study's

184 participants due to infants being born premature, not being at the age at which to safely feed

185 orally, and presenting concerns with sucking, swallowing, and breathing coordination (Gewolb et

186 al., 2001; Harding et al, 2018). We chose to use the NBAS since it takes into consideration the

187 following factors that influence feeding behaviors in infants: habituation, social interaction,

188 motor system, state regulation and organization, autonomic nervous system, reflexes and

189 supplementary items (Sakalidis \& Geddes, 2016). A researcher who had completed a specialist

190 NBAS assessment course at the Cambridge Brazelton Centre UK performed the NBAS

191 assessment with the study's participants. Each neonate was assessed and then placed on a flat,

192 comfortable surface of an incubator cot. Other parameters considered during the study were

193 umbilical cord arterial $\mathrm{pH}$ (collected at birth), birth weight, gestational age at birth, and age at

194 assessment.

\section{Analytic Strategy}

196 Statistical analysis was performed using Statistica Version 13 software (TIBCO Software,

197 Tulsa, USA). The correlation between samples was measured using Spearman's rank

198 correlation, and a $\mathrm{p}$ value $<0.05$ was considered statistically significant. A non-parametric

199 Mann-Whitney U test was used to test for group differences in continuous variables.

200 The study was approved by the Bioethics Committee, consent ref. no. 734/19.

201 Results

202 According to the results from the NBAS assessment as shown in in Table 1, the sucking

203 reflex was present in 84 out of the 100 children assessed. There was a statistically significant

204 correlation between the presence of the sucking reflex and the value of umbilical cord arterial $\mathrm{pH}$

$205(p=0.018 ; \mathrm{r}=0.32)$. However, there was no correlation found between other factors such as 
206 gestational age at birth, age during the assessment, birth weight, and presence of the sucking

207 reflex (Table 1). We also observed that umbilical cord arterial $\mathrm{pH}$ was correlated with the

208 presence of asymmetric tonic neck reflex (ATNR), cost of attention, and motor maturity (Table

209 2). Other items from the NBAS such as habituation to sensory stimuli (i.e., Animate auditory,

210 animate visual, and inanimate visual), social interaction, state regulation and organization, as

211 well as autonomic nervous system items and most of the reflexes except for ATNR and other

212 supplementary items did not correlate with umbilical cord arterial $\mathrm{pH}$ value and the sucking

213 reflex.

\section{Discussion}

215 Understanding the sucking reflex in neonates is an important matter, as it forms part of

216 the coordination of sucking, swallowing and breathing essential for breast or bottle feeding

217 (Sakalidis \& Geddes, 2016). There are many factors that may influence the process of feeding an

218 infant. Factors known to be correlated with a delay in development of the sucking reflex include

219 prematurity or low birth weight (Kumar et al., 2017; Lau et al., 2000; Sakalidis et al., 2013).

220 However, these correlations are not demonstrated in the current study. The reason is that our

221 study is the relatively small size of the study group, therefore the results need to be confirmed in

222 the future on a larger study group and with multivariate analysis.

Sucking behavior must be coordinated with swallowing and respiration in order to ensure

224 the safe transport of food content from the mouth to the stomach (Lau, 2015). Such a complex

225 activity as bottle or breast feeding may be disrupted or unsuccessful following low umbilical

226 cord arterial $\mathrm{pH}$ which may lead to hypoxia or acidosis. An umbilical cord arterial $\mathrm{pH}$ lower than

2277 may indicate poor tissue perfusion and is associated with a higher incidence of intraventricular

228 hemorrhage (IVH) and cystic periventricular leukomalacia (Levene et al., 1982). An umbilical 
229 cord arterial $\mathrm{pH}$ lower than 7 can also indicate critical hypoxia, particularly of the brain.

230 Furthermore, this can lead to poor motor outcomes and neurodevelopmental disorders

231 (Robertson \& Perlman, 2006).

232 Our analysis indicates a correlation between umbilical cord arterial $\mathrm{pH}$ and the presence

233 of the sucking reflex. Umbilical cord arterial $\mathrm{pH}$ may be correlated with several neonatal

234 complications (Mitra et al., 2019). Primitive reflexes and postural reactions help to assess central

235 nervous system integrity (Hankins \& Speer, 2003; Mandich et al., 1994). Therefore, it is

236 essential to assess the sucking reflex as an element of neurobehavior in infants. Many aspects of

237 infant behavior may influence the sucking reflex, such as gestational age (Franco et al., 2004).

238 Pineda et al. (2019) showed that stable sucking pressure was related to feeding success only at

239 the $38^{\text {th }}$ week of gestation despite the research group consisting of neonates born before the $32^{\text {nd }}$

240 week of gestation. In our research group most of the children were younger than 38 weeks of

241 gestation. The average week of gestation was 31,8 (approximately the $32^{\text {nd }}$ week) and the

242 average age during the study was 34 weeks of gestation. This may attribute to the fact that there

243 was no significant difference found between age at birth and age at assessment. Another variable

244 of our research group that we suspected to differ in the presence of the sucking reflex was birth

245 weight. We found that the frequency of sucking behavior increased with gestational age as in the

246 study conducted by Cunha et al. (2009). However, we identified no correlation between sucking

247 behavior and birth weight, as similar to the findings from the study of Psaila et al. (2014).

248 We suspected that poor reaction to sensory stimuli would be associated with a lack of a

249 sucking reflex. It is well known that preterm neonates tend to present problems with behavioral

250 responses to sensory stimuli (Rahkonen et al., 2015). Sucking and swallowing reflexes are

251 complex and involve sensory afferent nerve fibers. The integration of sensory and motor 
252 functions is essential to the development of normal sucking and later feeding skills (Neel et al.,

253 2019; Stevenson \& Allaire, 1991). Most of the infants in our study group were born preterm.

254 This is why the assessed response to sensory stimuli as the element of habituation and social

255 interactive items were similar and did not affect the correlation with sucking. However, we know

256 that the development of feeding skills is an extremely complex process influenced by multiple

257 factors, including social factors. Atypical early sensory experiences in the neonatal unit alters

258 others developmental processes such as state regulation (Litt et al., 2019; Neel et al., 2019). The

259 NBAS enables us to assess an infant's state, which is essential when development feeding

260 programs. The misinterpretation of an infant's state, for instance crying, may lead to problems

261 with feeding including breastfeeding (Neifert \& Bunik, 2013). However, in the present study

262 most of the neonates were born preterm and had problems with state regulation. This is why we

263 suspect that the state regulation itself did not affect sucking ability.

264 Immaturity of the nervous system, including the autonomic nervous system (ANS),

265 characterizes preterm infants (Malak et al., 2020). Franco et al. (2004) showed that non-nutritive

266 sucking regulated ANS parameters. Lappi et al. (2007) demonstrated that sucking behavior

267 imposed physical strain on the baby, with a specific ANS response. However, our study did not

268 show any relationship between sucking behavior and ANS items of the NBAS. The preterm

269 infants in this study very often presented with hyperstimulation of sympathetic ANS. Due to

270 almost all of the infants in our study being born preterm, out study population was homogeneous

271 due to the immaturity of the ANS and poor state regulation.

272 Asymmetric tonic neck reflex (ATNR) is another component of neurobehavior related to

273 the primitive development of coordination. ATNR should appear at birth or in the first month of

274 life and disappears after six months of life. ATNR is demonstrated with the infant in a supine 
275 position. When the head is rotated, extension of the limbs is seen on the side to which the face is

276 turned, and flexion of the limbs is seen on the contralateral side (Zafeiriou, 2004). Our study

277 showed a correlation between umbilical cord arterial $\mathrm{pH}$ and the appearance of ATNR.

278 Observation of ATNR can also reveal reciprocal activity (Tokunaga et al., 2019). This is

279 evidence that adequate neuromuscular coordination is required for ATNR (Figueras et al., 2011;

280 Zafeiriou, 2004).

281 Other research has also shown that a relationship exists between automatic postural

282 reactions and motor development (Mandich et al., 1994; Mitra et al., 2019). Similarly, motor

283 maturity has been shown to be correlated with an umbilical cord arterial $\mathrm{pH} \geq 7.00$ (Figueras et

284 al., 2011). When an infant is being assessed using the NBAS, is it important to note if

285 movements are smooth and balanced with free arcs (45-90 degrees) or whether movement is

286 jerky with restricted arcs which can indicate immaturity. A higher NBAS score means that the

287 infant presents mature movements (Tokunaga et al., 2019). In this study, a higher NBAS score

288 and greater motor maturity was correlated with a higher umbilical cord arterial $\mathrm{pH}$. Other studies

289 have also shown that umbilical cord arterial $\mathrm{pH}$ may be a determinant of motor development

290 (Baschat, 2011).

291

Another aspect of NBAS which was correlated with umbilical cord arterial $\mathrm{pH}$ was the

292 cost of attention. These are features which may appear in the neonate which should be

293 considered as state overloading. Cost of attention includes observing if the infant is extremely

294 pale or if he or she shows acrocyanosis or mottled skin. Motor exhaustion, flaccidity,

295 hypertonicity and tremors should also be taken into consideration, particularly if an infant's

296 smooth movements turn into jerky and ineffective movements. The correlation between cost of

297 attention and umbilical cord arterial $\mathrm{pH}$ is not surprising if we assume that an umbilical cord 
298 arterial $\mathrm{pH} \leq 7.00$ is a predictor of adverse neonatal outcomes and is an accurate screening test

299 for neonatal hypoxia (Robertson \& Perlman, 2006).

300 Infant motor development includes not only reflexes but also perception, planning and

301 motivation. More and more evidence demonstrates that, from birth onwards, babies are subjects

302 who act on the world (Baschat, 2011). Delays in motor development, including reflexes, such as

303 sucking, are associated with the presence of neurodevelopmental disorders (Diamond, 2000).

304 Capilouto et al. (2017) found that the sucking reflex was a marker for later neurodevelopmental

305 outcomes and is an early marker of overall central nervous system integrity. The lack of an

306 effective sucking reflex was associated with an observed motor developmental delay at 18

307 months, two years and even three years (Capilouto et al., 2017).

308 Limitations

309 One limitation of our study is the relatively small sample size of the study group.

310 Therefore, the results need to be confirmed in the future to a larger study group and with

311 multivariate analysis.

\section{Conclusions}

313 Observation of an infant's neurobehavior, including the sucking reflex, is essential to

314 planning and approaching therapeutic feeding interventions, particularly when an infant is

315 discharged home. The NBAS allows the practitioner and parent to observe and assess the

316 abilities and communication of a neonate, and increase his or her ability to engage in appropriate

317 feeding behaviors. This has an added benefit of decreasing the stress of the parent during times

318 when the neonate must feed. Additionally, different aspects should be considered in the

319 assessment of sucking behavior such as ATNR, motor maturity, and cost of attention. 
321 reflex in the first moments of life and identify any disorders. Clinicians can then communicate

322 findings to the parents and explain aspects that need facilitation. A priority in neonatal care

323 should be allowing parents to spend time with their child in a safe way (Fonfe et al., 2021).

324 Moreover, it is important to shorten the length of time a child is separated from his or her family.

325 This is of particular importance during the COVID-19 pandemic when parents cannot be present

326 in the neonatal ward. The NBAS helps parents to identify the neonatal state. Although not all

327 infants who leave neonatal care will go home fully orally fed, the NBAS will support parents in

328 identifying infant states as an important part of oral feeding and oral care development (Harding

329 et al., 2015).

\section{Acknowledgements}

331 This study was undertaken with the contribution of nurses and neonatologists from the

332 neonatology clinic who were involved in the preparation of each neonate for neurobehavioral

333 assessment. Special thanks to the nurses and neonatologists at the Gynecology and Obstetrics

334 Hospital in Poznań. 


\section{References}

336 Barton, C., Bickell, M., \& Fucile, S. (2018). Pediatric oral motor feeding assessments: A systematic review. Physical \& Occupational Therapy in Pediatrics, 38(2), 190-209. https://doi.org/10.1080/01942638.2017.1290734

339

340

341

342

343

344

Baschat, A. A. (2011). Neurodevelopment following fetal growth restriction and its relationship with antepartum parameters of placental dysfunction. Ultrasound in Obstetrics and Gynecology, 37(5), 501-514. https://doi.org/10.1002/uog.9008

Belot, R. A., Bouteloup, M., Mariage, A., Candilis-Huisman, D., Mottet, N., \& Mellier, D. (2021). Relevance of Neonatal Behavior Assessment Scale for infants with somatic disorders: Comparison on one matched group of control. Frontiers in Pediatrics, 8 , 506384. https://doi.org/10.3389/fped.2020.506384

Bond, L. E., Mayerl, C. J., Stricklen, B. M., German, R. Z., \& Gould, F. (2020). Changes in the coordination between respiration and swallowing from suckling through weaning. Biology Letters, 16(4), 20190942. https://doi.org/10.1098/rsbl.2019.0942

Brazelton, T. B. \& Nugent, J. K. (2011). Neonatal Behavioral Assessment Scale (4th Edition). Mac Keith Press.

Bülow, M., Olsson, R., \& Ekberg, O. (2001). Videomanometric analysis of supraglottic swallow, effortful swallow, and chin tuck in patients with pharyngeal dysfunction. Dysphagia, 16(3), 190-195. https://doi.org/10.1007/s00455-001-0065-9

Capilouto, G. J., Cunningham, T. J., Mullineaux, D. R., Tamilia, E., Papadelis, C., \& Giannone, P. J. (2017). Quantifying neonatal sucking performance: Promise of new methods. Seminars in Speech and Language, 38(2), 147-158. https://doi.org/10.1055/s-00371599112 
358 Clark, L., Kennedy, G., Pring, T., \& Hird, M. (2007). Improving bottle feeding in preterm

359 infants: Investigating the elevated side-lying position. Infant, 3(4), 154-158.

360 Clawson, B., Selden, M., Lacks, M., Deaton, A. V, Hall, B., \& Bach, R. (2008). Complex

361 pediatric feeding disorders: using teleconferencing technology to improve access to a

362 treatment program. Pediatric Nursing, 34(3), 213-216.

363 Colson, S. D., Meek, J. H., \& Hawdon, J. M. (2008). Optimal positions for the release of

364 primitive neonatal reflexes stimulating breastfeeding. Early Human Development, 84(7),

365 441-449. https://doi.org/10.1016/j.earlhumdev.2007.12.003

366 Cunha, M., Barreiros, J., Gonçalves, I., \& Figueiredo, H. (2009). Nutritive sucking pattern-

367 from very low birth weight preterm to term newborn. Early Human Development, 85(2),

368 125-130. https://doi.org/10.1016/j.earlhumdev.2008.07.003

369 da Costa, S. P., van den Engel-Hoek, L., \& Bos, A. F. (2008). Sucking and swallowing in infants

$370 \quad$ and diagnostic tools. Journal of Perinatology, 28(4), 247-257.

371 https://doi.org/10.1038/sj.jp.7211924

372 Desai, H., \& Lim, A. N. (2019). Neurodevelopmental intervention strategies to improve oral

373 feeding skills in infants with congenital heart defects. Perspectives of the ASHA Special

374 Interest Groups, 4, 1492-1497. https://doi.org/10.1044/2019_PERS-SIG13-2019-

$375 \quad 0017$

376 Diamond, A. (2000). Close interrelation of motor development and cognitive development and

377 of the cerebellum and prefrontal cortex. Child Development, 71(1), 44-56.

$378 \quad$ https://doi.org/10.1111/1467-8624.00117

379 Dodrill, P., McMahon, S., Donovan, T., \& Cleghorn, G. (2008). Current management of

380 transitional feeding issues in preterm neonates born in Queensland, Australia. Early 
382 Erlandsson, K., Dsilna, A., Fagerberg, I., \& Christensson, K. (2007). Skin-to-skin care with the father after cesarean birth and its effect on newborn crying and prefeeding behavior. Birth

Figueras, F., Cruz-Martinez, R., Sanz-Cortes, M., Arranz, A., Illa, M., Botet, F., Costas-

Fonfe, A., Clements, D., \& Mckechnie, L. (2021) Parental access to neonatal units: Inconsistency during the COVID-19 pandemic. Infant Journal, 17(2), 71-75.

391 Foster, J. P., Psaila, K., \& Patterson, T. (2016). Non-nutritive sucking for increasing physiologic 392

Franco, P., Chabanski, S., Scaillet, S., Groswasser, J., \& Kahn, A. (2004). Pacifier use modifies stability and nutrition in preterm infants. The Cochrane Database of Systematic Reviews, 10(10), CD001071. https://doi.org/10.1002/14651858.CD001071.pub3

Gewolb, I. H., \& Vice, F. L. (2006). Maturational changes in the rhythms, patterning, and coordination of respiration and swallow during feeding in preterm and term infants. Developmental Medicine \& Child Neurology, 48(7), 589-594. doi: $10.1017 / \mathrm{S} 001216220600123 \mathrm{X}$ Developmental patterns of rhythmic suck and swallow in preterm infants. Developmental Medicine \& Child Neurology, 43(1), 22-27. https://doi.org/10.1017/s0012162201000044 
404 Greene, Z., O'Donnell, C. P., \& Walshe, M. (2016). Oral stimulation for promoting oral feeding 405 in preterm infants. The Cochrane Database of Systematic Reviews, 9(9), CD009720. doi:

406

407

408

409

410

411

412

413

414

415

416

417

418

419

420

421

422

423

424

425

426 10.1002/14651858.CD009720.pub2

Hankins, G. D. \& Speer, M. (2003). Defining the pathogenesis and pathophysiology of neonatal encephalopathy and cerebral palsy. Obstetrics and Gynecology, 102(3), 628-636. https://doi.org/10.1016/s0029-7844(03)00574-x

Harding, C., Cockerill, H., Cane, C., \& Law, J. (2018). Using non-nutritive sucking to support feeding development for premature infants: A commentary on approaches and current practice. Journal of Pediatric Rehabilitation Medicine, 11(3), 147-152. doi: 10.3233/prm170442

Harding, C., Frank, L., Botting, N., \& Hilari, K. (2015). Assessment and management of infant feeding. Infant, 11(3), 85-89.

Kirk, A. T., Alder, S. C., \& King, J. D. (2007). Cue-based oral feeding clinical pathway results in earlier attainment of full oral feeding in premature infants. Journal of Perinatology: Official Journal of the California Perinatal Association, 27(9), 572-578. https://doi.org/10.1038/sj.jp.7211791

Kumar, R. K., Singhal, A., Vaidya, U., Banerjee, S., Anwar, F., \& Rao, S. (2017). Optimizing nutrition in preterm low birth weight infants-Consensus wummary. Frontiers in Nutrition, 4, 20. https://doi.org/10.3389/fnut.2017.00020

Lappi, H., Valkonen-Korhonen, M., Georgiadis, S., Tarvainen, M. P., Tarkka, I. M., Karjalainen, P. A., \& Lehtonen, J. (2007). Effects of nutritive and non-nutritive sucking on infant heart rate variability during the first 6 months of life. Infant behavior \& development, 30(4), 546-556. https://doi.org/10.1016/j.infbeh.2007.04.005 
427 Lau, C. (2015). Development of suck and swallow mechanisms in infants. Annals of Nutrition $428 \quad$ and Metabolism, 66, 7-14. https://doi.org/10.1159/000381361

429 Lau, C., Alagugurusamy, R., Schanler, R. J., Smith, E. O., \& Shulman, R. J. (2000).

430 Characterization of the developmental stages of sucking in preterm infants during bottle 431 feeding. Acta Paediatrica, International Journal of Paediatrics, 89(7), 846-852. https://doi.org/10.1111/j.1651-2227.2000.tb00393.x

433 Levene, M. I., Fawer, C. L., \& Lamont, R. F. (1982). Risk factors in the development of 434 435 intraventricular haemorrhage in the preterm neonate. Archives of Disease in Childhood, 57(6), 410-417. https://doi.org/10.1136/adc.57.6.410

Li, X. L., Liu, Y., Liu, M., Yang, C. Y., \& Yang, Q. Z. (2020). Early premature infant oral motor intervention improved oral feeding and prognosis by promoting neurodevelopment. American Journal of Perinatology, 37(6), 626-632. https://doi.org/10.1055/s-0039-1685448

Litt, J. S., Ho, T., Obregon, E., Patel, P., Ziyeh, T., \& McCormick, M. C. (2019). Characterizing early state regulation in preterm infants. Journal of Developmental and Behavioral

Malak, R., Kozłowska, Z., Owsiańska, Z., Sikorska, D., Andrusiewicz, M., Szymankiewiczduring cranial osteopathic CV4 procedure in newborns. Advances in Clinical and Experimental Medicine, 29(10), 1187-1191. https://doi.org/10.17219/acem/126048 development, infantile reactions and postural responses of preterm, at-risk infants. Developmental Medicine and Child Neurology, 36(5), 397-405. 
https://doi.org/10.1111/j.1469-8749.1994.tb11865.x

451

452

453

454

McGrath, J. M. \& Braescu, A. V. (2004). State of the science: Feeding readiness in the preterm infant. The Journal of Perinatal \& Neonatal Nursing, 18(4), 353-370. https://doi.org/10.1097/00005237-200410000-00006

Mitra, S., Kendall, G. S., Bainbridge, A., Sokolska, M., Dinan, M., Uria-Avellanal, C., Price, D., Mckinnon, K., Gunny, R., Huertas-Ceballos, A., Golay, X., \& Robertson, N. J. (2019). Proton magnetic resonance spectroscopy lactate/N-acetylaspartate within 2 weeks of birth accurately predicts 2 -year motor, cognitive and language outcomes in neonatal encephalopathy after therapeutic hypothermia. Archives of Disease in Childhood. Fetal and Neonatal Edition, 104(4), F424-F432. https://doi.org/10.1136/archdischild-2018315478

Neel, M. L., Yoder, P., Matusz, P. J., Murray, M. M., Miller, A., Burkhardt, S., Emery, L., Hague, K., Pennington, C., Purnell, J., Lightfoot, M., \& Maitre, N. L. (2019). Randomized controlled trial protocol to improve multisensory neural processing, language and motor outcomes in preterm infants. BMC pediatrics, $19(1), 81$. https://doi.org/10.1186/s12887-019-1455-1

Neifert, M. \& Bunik, M. (2013). Overcoming clinical barriers to exclusive breastfeeding. Pediatric Clinics of North America, 60(1), 115-145. https://doi.org/10.1016/j.pcl.2012.10.001

Ohnishi, S., Ichiba, H., Tanaka, Y., Harada, S., Matsumura, H., Kan, A., Asada, Y., \& Shintaku, H. (2016). Early and intensive nutritional strategy combining parenteral and enteral feeding promotes neurodevelopment and growth at 18 months of corrected age and 3 years of age in extremely low birth weight infants. Early Human Development, 100, 35- 
41. https://doi.org/10.1016/j.earlhumdev.2016.03.014

474

475

476

477

478

479

480

481

482

483

484

485

486

487

488

489

490

491

492

493

494

495

Park, S., Cho, J. Y., Lee, B. J., Hwang, J. M., Lee, M., Hwang, S. Y., Kim, K., Lee, K. H., \& Park, D. (2020). Effect of the submandibular push exercise using visual feedback from pressure sensor: An electromyography study. Scientific Reports, 10(1), 11772. https://doi.org/10.1038/s41598-020-68738-0

Pineda, R., Dewey, K., Jacobsen, A., \& Smith, J. (2019). Non-nutritive sucking in the preterm infant. American Journal of Perinatology, 36(3), 268-276. https://doi.org/10.1055/s0038-1667289

Poore, M., Zimmerman, E., Barlow, S. M., Wang, J., \& Gu, F. (2008). Patterned orocutaneous therapy improves sucking and oral feeding in preterm infants. Acta Paediatrica: Nurturing the Child, 97(7), 920-927. https://doi.org/10.1111/j.1651-2227.2008.00825.x

Psaila, K., Foster, J. P., Richards, R., \& Jeffery, H. E. (2014). Non-nutritive sucking for gastrooesophageal reflux disease in preterm and low birth weight infants. The Cochrane Database of Systematic Reviews, (10), CD009817. https://doi.org/10.1002/14651858.CD009817.pub2

Ra, J. Y., Hyun, J. K., Ko, K. R., \& Lee, S. J. (2014). Chin tuck for prevention of aspiration: Effectiveness and appropriate posture. Dysphagia, 29(5), 603-609. https://doi.org/10.1007/s00455-014-9551-8

Rahkonen, P., Lano, A., Pesonen, A. K., Heinonen, K., Räikkönen, K., Vanhatalo, S., Autti, T., Valanne, L., Andersson, S., \& Metsäranta, M. (2015). Atypical sensory processing is common in extremely low gestational age children. Acta paediatrica (Oslo, Norway : 1992), 104(5), 522-528. https://doi.org/10.1111/apa.12911

Redstone, F. \& West, J. (2004). The importance of postural control for feeding. Pediatric 
Nursing, 30(2). 97-100.

497 Reissland, N., Mason, C., Schaal, B., \& Lincoln, K. (2012). Prenatal mouth movements: Can

498 we identify co-ordinated fetal mouth and LIP actions necessary for feeding?

499 International Journal of Pediatrics, 1-5. https://doi.org/10.1155/2012/848596

500

Robertson, C. M. T., \& Perlman, M. (2006). Follow-up of the term infant after hypoxic-

501

502 ischemic encephalopathy. Paediatrics and Child Health, 11(5), 278-282.

Sakalidis, V. S. \& Geddes, D. T. (2016). Suck-swallow-breathe dynamics in breastfed infants. https://doi.org/10.1093/pch/11.5.278 Journal of Human Lactation: Official Journal of International Lactation Consultant

Sakalidis, V. S., Williams, T. M., Hepworth, A. R., Garbin, C. P., Hartmann, P. E., Paech, M. J., Association, 32(2), 201-211; quiz 393-395. https://doi.org/10.1177/0890334415601093 Al-Tamimi, Y., \& Geddes, D. T. (2013). A comparison of early sucking dynamics during

511 Salandy, S., Rai, R., Gutierrez, S., Ishak, B., \& Tubbs, R. S. (2019). Neurological breastfeeding after cesarean section and vaginal birth. Breastfeeding Medicine: The Official Journal of the Academy of Breastfeeding Medicine, 8(1), 79-85.

Simpson, C., Schanler, R. J., \& Lau, C. (2002). Early introduction of oral feeding in preterm examination of the infant: A comprehensive review. Clinical Anatomy (New York, infants. Pediatrics, 110(3), 517-522. https://doi.org/10.1542/peds.110.3.517

Sink, D. W., Hope, S. A. E., \& Hagadorn, J. I. (2011). Nurse: Patient ratio and achievement of oxygen saturation goals in premature infants. Archives of Disease in Childhood-Fetal and Neonatal Edition, 96(2), F93-F98. https://doi.org/10.1136/adc.2009.178616 
519 Stevenson, R. D., \& Allaire, J. H. (1991). The development of normal feeding and swallowing.

$520 \quad$ Pediatric Clinics of North America, 38(6), 1439-1453. https://doi.org/10.1016/s0031-

$521 \quad 3955(16) 38229-3$

522 The Emily Center at Phoenix's Children's Hospital. (2016). Positions to help your baby drink 523 from a bottle. https://www.phoenixchildrens.org/files/inline-files/Positions-to-Help-YourBaby-Drink-From-a-Bottle-219.pdf

525

526

527

528

529

530

531

532

533

534

535

536

537

538

539

540

541

Tokunaga, A., Akiyama, T., Miyamura, T., Honda, S., Nakane, H., Iwanaga, R., \& Tanaka, G. (2019). Neonatal behavior and social behavior and sensory issues in 18-month toddlers. Pediatrics International, 61(12), 1202-1209. https://doi.org/10.1111/ped.14033

Versfeld, P. (2018, January 1). Task oriented movement therapy: Development of head control: Neonate-3 months. Skills for Action. https://tomt.skillsforaction.com/blog/developmenthead-control

Welch, M. V., Logemann, J. A., Rademaker, A. W., \& Kahrilas, P. J. (1993). Changes in pharyngeal dimensions effected by chin tuck. Archives of Physical Medicine and Rehabilitation, 74(2), 178-181.

White-Traut, R. C., Berbaum, M. L., Lessen, B., McFarlin, B., \& Cardenas, L. (2005). Feeding readiness in preterm infants: the relationship between preterm behavioral state and feeding readiness behaviors and efficiency during transition from gavage to oral feeding. MCN: The American Journal of Maternal/Child Nursing, 30(1), 52-59.

Wolthuis-Stigter, M. I., Luinge, M. R., da Costa, S. P., Krijnen, W. P., van der Schans, C. P., \& Bos, A. F. (2015). The association between sucking behavior in preterm infants and neurodevelopmental outcomes at 2 years of age. The Journal of Pediatrics, 166(1), 26-30. https://doi.org/10.1016/j.jpeds.2014.09.007 
542 Yoon, W. L., Khoo, J. K., \& Rickard Liow, S. J. (2014). Chin tuck against resistance (CTAR):

543 New method for enhancing suprahyoid muscle activity using a Shaker-type

544 exercise. Dysphagia, 29(2), 243-248. https://doi.org/10.1007/s00455-013-9502-9

545 Zafeiriou, D. I. (2004). Primitive reflexes and postural reactions in the neurodevelopmental

546 examination. Pediatric Neurology, 31(1), 1-8.

$547 \quad$ https://doi.org/10.1016/j.pediatrneurol.2004.01.012

548 Zhang, X., Zhou, M., Yin, H., Dai, Y., \& Li, Y. (2017). The predictive value of early oral motor

549 assessments for neurodevelopmental outcomes of moderately and late preterm infants.

$550 \quad$ Medicine (United States), 96(50). https://doi.org/10.1097/MD.0000000000009207 


\section{Table 1 (on next page)}

The relationship between sucking and perinatal data. 
2 Table 1. The relationship between sucking and perinatal data.

\begin{tabular}{|l|l|l|}
\hline Interview data & r Spearman value & $p$ value \\
\hline Gestation age & 0.11 & 0.337654 \\
\hline The age during the assessment & 0.05 & 0.795217 \\
\hline Umbilical cord artery $\mathrm{pH}$ & 0.32 & 0.018981 \\
\hline The birth weight & 0.13 & 0.201785 \\
\hline
\end{tabular}




\section{Table 2 (on next page)}

The relationship between items of Neonatal Behavioral Assessment Scale and the level of umbilical cord artery. 
1 Table 2. The relationship between items of Neonatal Behavioral Assessment Scale and the level

2 of umbilical cord artery.

3

\begin{tabular}{l|l|l}
\hline $\begin{array}{l}\text { Items of Neonatal Behavior } \\
\text { Assessment Scale }\end{array}$ & $p$-value & r Spearman \\
\hline Asymmetric Tonic Neck Reflex & 0,04 & 0,27 \\
\hline Cost of attention & 0,02 & 0,30 \\
\hline Motor maturity & 0,01 & 0,34 \\
\hline $\begin{array}{l}\text { Autonomic system, } \\
\text { tremulousness }\end{array}$ & 0,73 & 0,04 \\
\hline Autonomic system, startless & 0,11 & 0,22 \\
\hline $\begin{array}{l}\text { Autonomic system, lability of } \\
\text { skin colour }\end{array}$ & 0,42 & 0,11 \\
\hline State regulation & 0,72 & 0,04 \\
\hline Lability of state & 0,29 & 0,29 \\
\hline Animate auditory & 0,52 & 0,08 \\
\hline Animate visual & 0,50 & 0,09 \\
\hline Inanimate visual & 0,26 & 0,15 \\
\hline
\end{tabular}

4 